\title{
Large-Scale Atmospheric Step-and-Repeat UV Nanoimprinting
}

\author{
Kentaro Ishibashi, ${ }^{1,2}$ Hiroshi Goto, ${ }^{2}$ Jun Mizuno, ${ }^{3}$ and Shuichi Shoji ${ }^{1}$ \\ ${ }^{1}$ Department of Nanoscience and Nanoengineering, Waseda University, 3-4-1, Okubo, Shinjuku, Tokyo 169-8555, Japan \\ ${ }^{2}$ Nano Processing System Division, Toshiba-Machine Co., Ltd., 2068-3 Ooka, Numazu, Shizuoka 410-8510, Japan \\ ${ }^{3}$ Institute for Nanoscience and Nanotechnology, Waseda University, 513 Waseda Tsurumaki-cho, Shinjuku, Tokyo 162-0041, Japan \\ Correspondence should be addressed to Kentaro Ishibashi, k.ishibashi2@akane.waseda.jp
}

Received 25 November 2011; Accepted 14 July 2012

Academic Editor: Kyoung Moon

Copyright ( $\odot 2012$ Kentaro Ishibashi et al. This is an open access article distributed under the Creative Commons Attribution License, which permits unrestricted use, distribution, and reproduction in any medium, provided the original work is properly cited.

Step-and-repeat UV nanoimprinting for large-scale nanostructure fabrication under atmospheric pressure was realized using highviscosity photocurable resin and a simple nanoimprinting system. In step-and-repeat UV nanoimprinting under atmospheric pressure using low-viscosity resin, large-scale nanostructure fabrication is very difficult, due to bubble defects and nonuniformity of the residual layer. To minimize bubble defects and nonuniformity of the residual layer, we focused on the damping effects of photocurable resin viscosity. Fabrication of 165 dies was successfully demonstrated in a $130 \times 130 \mathrm{~mm}^{2}$ area on an 8 in silicon substrate by step-and-repeat UV nanoimprinting under atmospheric pressure using high-viscosity photocurable resin. Nanostructures with widths and spacing patterns from $80 \mathrm{~nm}$ to $3 \mu \mathrm{m}$ and $200 \mathrm{~nm}$ depth were formed using a quartz mold. Bubble defects were not observed, and residual layer uniformity was within $30 \mathrm{~nm} \pm 10 \%$. This study reports on simple step-and-repeat UV nanoimprinting under atmospheric pressure using high-viscosity photocurable resin, as a very widely available method for large-scale mass production of nanostructures.

\section{Introduction}

The nanoimprinting process is well known as a highthroughput, low-cost, and developing nanostructure technology affecting not only integrated semiconductor circuits but also the commercialization of many innovative devices $[1,2]$. Therefore, the nanoimprinting process is required for mass production of next-generation high-throughput, lowcost, and energy-saving nanodevices, such as next-generation light emitting diodes (LEDs) [3-7], antireflection structures for solar cells [8-10], wire-grid polarizers for optoelectronic devices [11-13], and organic semiconductor devices [14]. In conventional low-pressure UV nanoimprinting, a mold with nanostructures is pressed onto a low-viscosity photocurable resin to form high-resolution nanostructures [15-19]. After resin curing and mold separation, the nanostructure is formed on the cured resin. Actually, in the case of lowviscosity UV nanoimprinting, bubble defects and nonuniform residual layers are very important problems. Bubble defect is a well-known problem in UV nanoimprinting under atmospheric pressure using low-viscosity photocurable resin.
To address this issue, UV nanoimprinting with the assistance of gas condensation and UV nanoimprinting under vacuum have been reported [20-23].

The nonuniform residual layer problem is very important to the reactive ion etching process. As a solution to the problem of nonuniformity in the residual layer, UV nanoimprinting using a complementary pattern mold has been reported [24].

Figure 1 shows a nonuniform residual layer in conventional low-pressure UV nanoimprinting with low-viscosity photocurable resin. Figure 1(a) shows a photographic image of $10 \times 10 \mathrm{~mm}^{2}$ area. Nonuniformity of the residual layer can be seen as fringes. After a reactive ion etching process, the pattern was not fabricated in the fringe area due to residual layer becoming nonuniform as shown in Figure 1(b). Figures 1(c) and 1(d) show cross-sectional scanning electron microscope (SEM) images of the same nanoimprinting area. These images show that the residual layer was not uniform but varied in thickness from 10 to $50 \mathrm{~nm}$.

However, the UV nanoimprinting process and system have become more complex and costly using these methods 


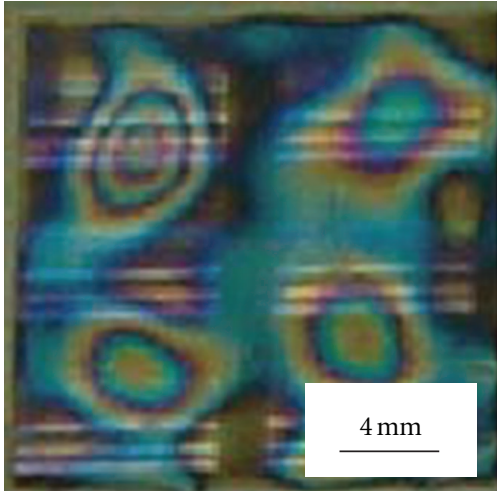

(a)

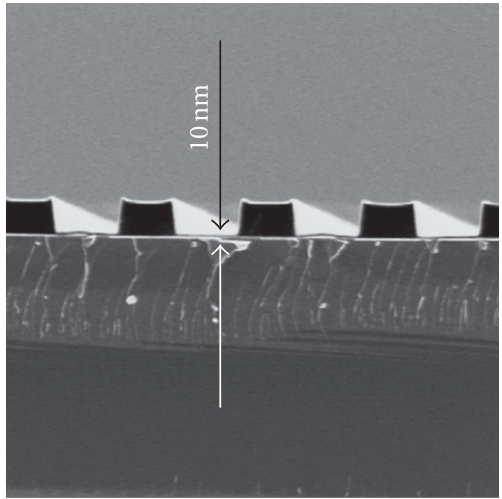

(c)

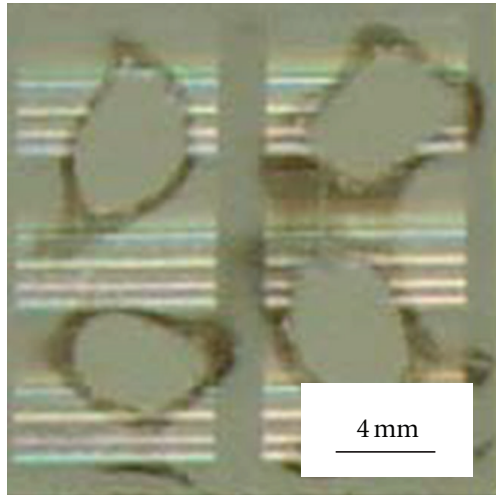

(b)

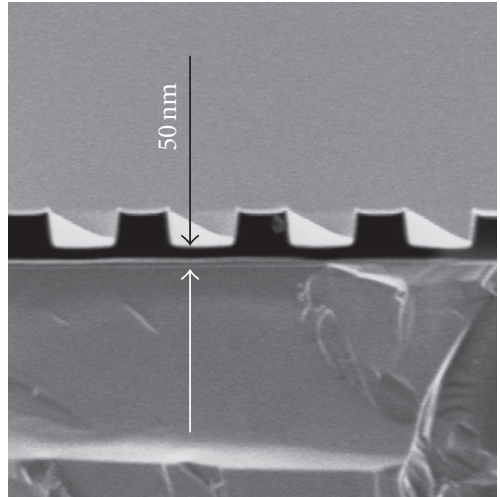

(d)

FIGURE 1: Nonuniform residual layer thickness, (a) nonuniform residual layer thickness appears as fringes, (b) pattern was not formed after reactive ion etching, (c) cross-sectional image, residual layer thickness was $10 \mathrm{~nm}$, and (d) cross-sectional image, residual layer thickness was $50 \mathrm{~nm}$.

and it is very difficult to apply it to large-scale nanostructure fabrication.

This study reports on a simple step-and-repeat UV nanoimprinting process using high-viscosity photocurable resin as a widely available method for next-generation mass production of large-scale nanostructures.

\section{Experimental Setup}

Figure 2 shows the original UV nanoimprinting system used in this study. It is a very simple nanoimprinting system that consists of a press platen in a double-column frame and an $x-y-\theta$ table without special equipment such as vacuum chamber. The mold is fixed under the press platen, and the substrate is fixed on the $x-y-\theta$ table [25]. The $x-y-\theta$ table used in the imprint system enables production of large-scale nanostructures by step-and-repeat operation. Figure 3 shows the distribution of platen position where the mold contacts the substrate. For flatness measurement, a $13 \times 13$ shots were demonstrated using a $10 \times 10 \mathrm{~mm}^{2}$ quartz mold by a stepand-repeat operation using the nanoimprinting system. The flatness between the mold and the substrate was optimized within $5 \mu \mathrm{m}$ in a $130 \times 130 \mathrm{~mm}^{2}$ area.

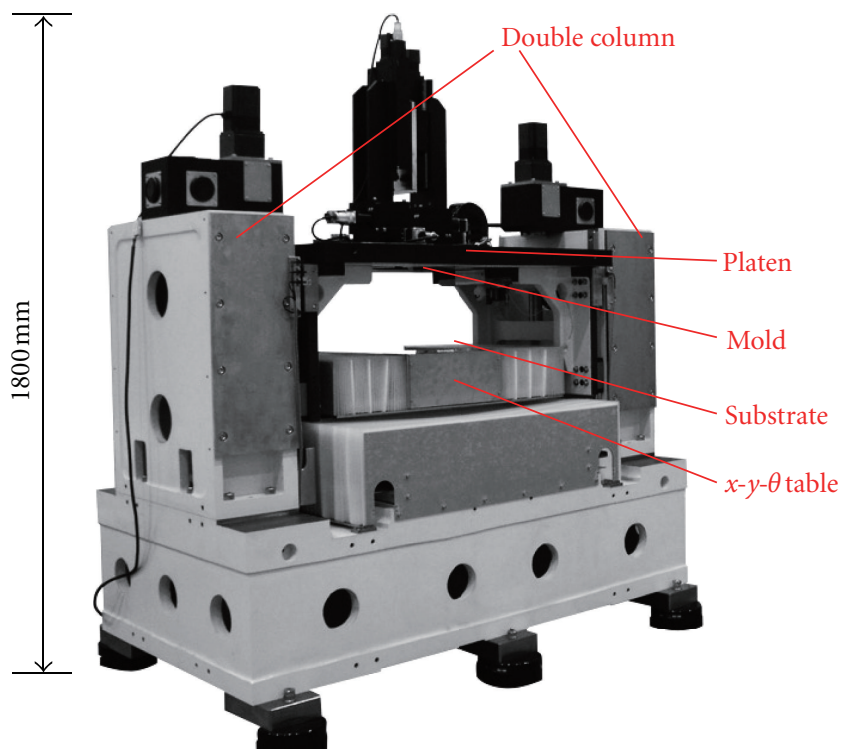

FIGURE 2: Nanoimprinting system: this system consists of a press platen in a double-column frame and an $x-y-\theta$ table. The quartz mold was fixed under the press platen, and the substrate was fixed on the $x-y-\theta$ table. 


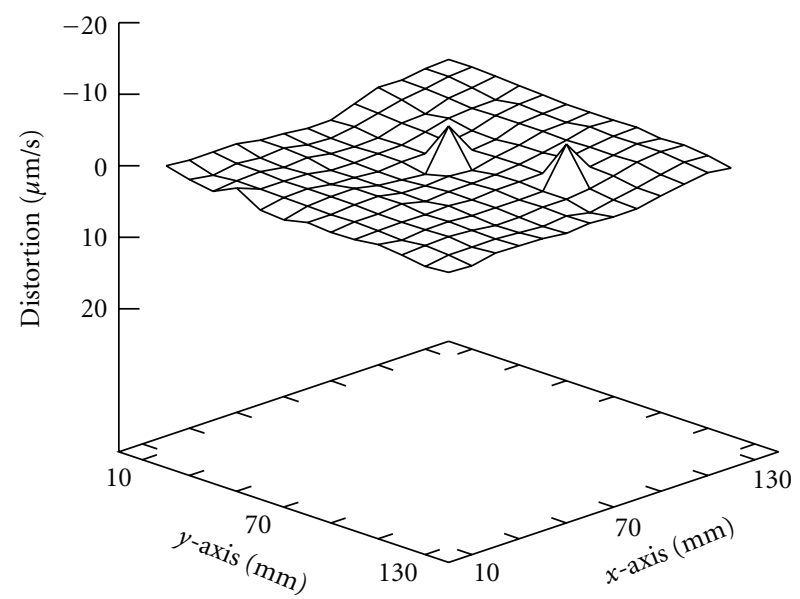

Figure 3: Distribution of press position: the flatness between the mold and the substrate was within $5 \mu \mathrm{m}$, in a $130 \times 130 \mathrm{~mm}^{2}$ area measured by step-and-repeat operation with the nanoimprinting system.

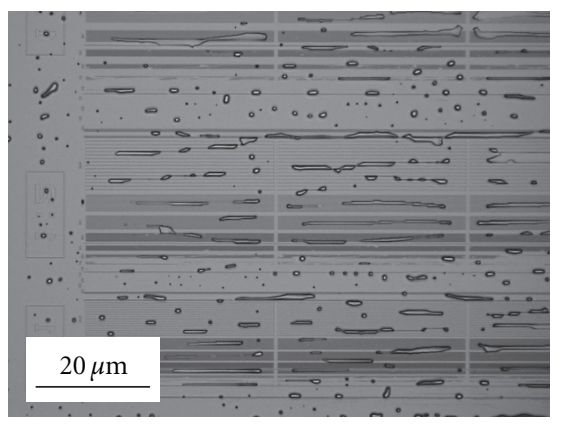

(a)

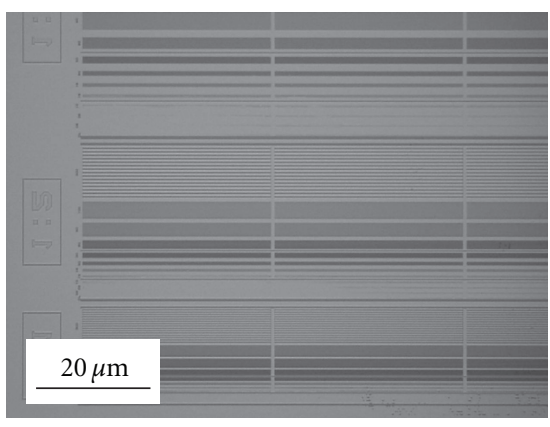

(b)

Figure 4: Bubble defects: (a) in the case of low-viscosity resin, bubble defects were observed, and (b) in case of high-viscosity resin, bubble defects were not observed.

\section{Examinations and Results}

To minimize bubble defects and nonuniformity in the residual layer, we focused on the viscosity of the photocurable resin. Evaluation of bubble defects was demonstrated using a quartz mold (NIM-80L RESO, NTT-Advanced Technology Co., Ltd.), silicon substrate, and photocurable resins with two different viscosities. The quartz mold size was $10 \times$ $10 \mathrm{~mm}^{2}$. Nanostructures with widths and spacing patterns from $80 \mathrm{~nm}$ to $3 \mu \mathrm{m}$ and $200 \mathrm{~nm}$ depth were fabricated on silicon substrates by UV nanoimprinting under atmospheric pressure. Nanoimprinting conditions were $2 \mathrm{MPa}$ of imprinting pressure and $1 \mu \mathrm{m} / \mathrm{s}$ of platen feed velocity, $360 \mathrm{~mJ} / \mathrm{cm}^{2}$ of exposure dose. The viscosity of the photocurable resin was $10 \mathrm{mPa} \cdot \mathrm{s}$ before baking. The resin was spin-coated to a thickness of $200 \mathrm{~nm}$ on a substrate. The photocurable resin thickness was changed by the baking from a $150 \mathrm{~nm}$ low-viscosity resin to a $120 \mathrm{~nm}$ high-viscosity resin. The viscosity of the photocurable resin was changed by the baking process, from a $1,200-\mathrm{mPa} \cdot \mathrm{s}$ low-viscosity resin to a $12,000-\mathrm{mPa} \cdot \mathrm{s}$ high-viscosity resin. Figure 4 shows a photographic image by optical microscopy. In the case of the low-viscosity resin, bubble defects were observed as shown in Figure 4(a). However, in the case the of highviscosity resin, bubble defects were not observed as shown in Figure 4(b). As indicated by Figure 4, bubble defects depended on the viscosity of the photocurable resin. To minimize nonuniformity in the residual layer, the relationship between residual layer uniformity and the viscosity of the photocurable resin was examined by UV nanoimprinting under atmospheric pressure. Nonuniformity of the residual layer was observed as a fringe which was represented by a 256-level gray-scale histogram. Figure 5 shows four gray-scale histograms from processed photo images of a $10 \times 10 \mathrm{~mm}^{2}$ area comprising 108,900 pixels. Imprinting conditions were $2 \mathrm{MPa}$ of imprinting pressure, $1 \mu \mathrm{m} / \mathrm{s}$ of platen feed velocity, and $200 \mathrm{~nm}$ of spin-coated photocurable resin thickness. Figure 5(a) shows a reference gray-scale histogram for the case without nanoimprinting, and a fringe was not observed, all 108,900 pixels were within 20 grayscale levels, and the nonuniformity of the residual layer was $0 \%$. In the case with low-viscosity, $1,200 \mathrm{mPa} \cdot \mathrm{s}$ of viscosity, a fringe was observed, the distribution of gray-scale levels was 103 levels, only 31,721 pixels were within 20 grayscale levels, and the nonuniformity of the residual layer was $71 \%$, as shown in Figure 5(b). Figure 5(c) shows gray-scale histogram, in the case with middle-viscosity, $5000 \mathrm{mPa} \cdot \mathrm{s}$ of viscosity, a fringe was observed, the distribution of gray-scale levels was 90 levels, 55,521 pixels were within 20 gray-scale levels, and the nonuniformity of the residual layer was $49 \%$. Conversely, in case of high-viscosity resin, $12,000 \mathrm{mPa} \cdot \mathrm{s}$ of viscosity, little fringe was observed, the distribution of grayscale levels was 37 levels, 103,352 pixels were within 20 grayscale levels, and the nonuniformity of the residual layer was $5 \%$, as shown in Figure $5(\mathrm{~d})$. As indicated by Figure 5, a uniform residual layer depends on the viscosity of the photocurable resin. Figure 6 shows the relationship between nonuniformity of the residual layer and imprinting pressure. The conditions of the nanoimprint were as follows: from 0.5 to $8 \mathrm{MPa}$ of imprinting pressure, $1 \mu \mathrm{m} / \mathrm{s}$ of platen feed velocity, $360 \mathrm{~mJ} / \mathrm{cm}^{2}$ of exposure dose. In the cases of lowviscosity and middle-viscosity, nonuniformity of the residual layer did not depend on imprinting pressure. However, in the case of high-viscosity resin, nonuniformity of the residual layer decreased with higher imprinting pressure, and nonuniformity of the residual layer was less than $10 \%$ with an imprinting pressure $\geq 2 \mathrm{MPa}$. As shown in Figure 6, nonuniformity of the residual layer depended 


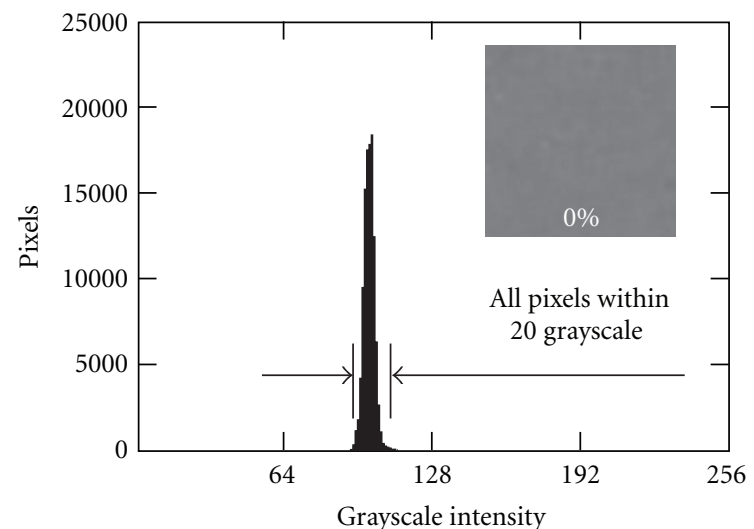

(a)

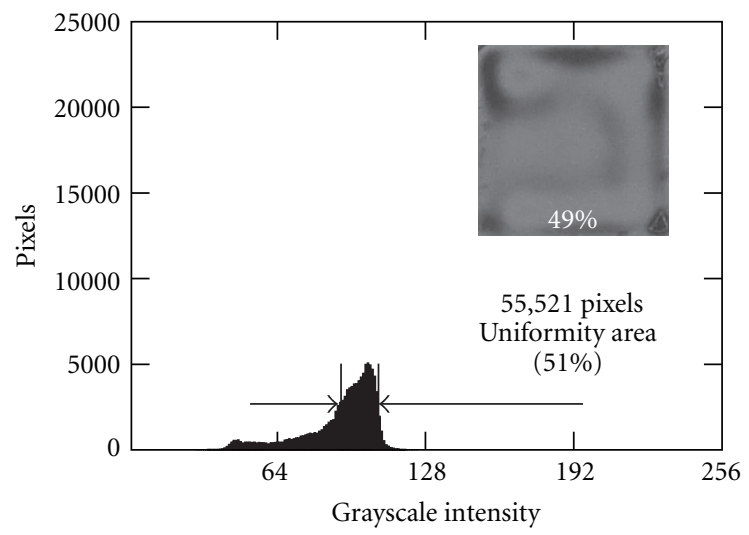

(c)

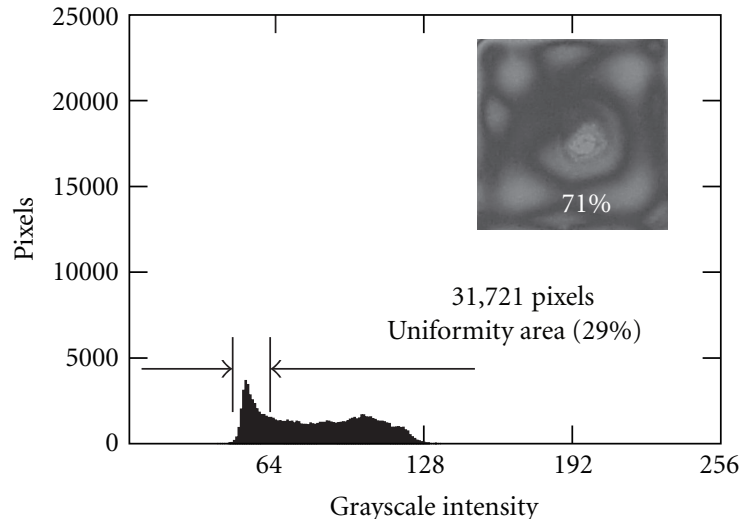

(b)

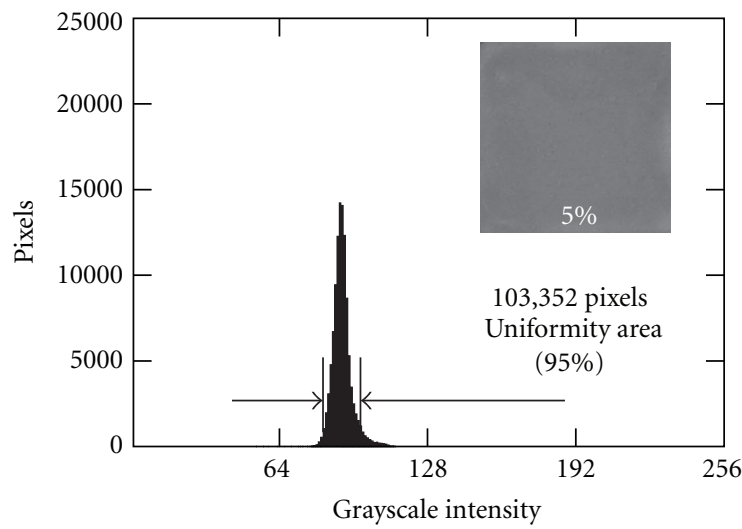

(d)

FIGURE 5: Examination of nonuniformity of the residual layer by gray-scale histogram: (a) reference gray-scale histogram, (b) with lowviscosity resin, nonuniformity of the residual layer was $71 \%$, (c) with middle-viscosity resin, nonuniformity of the residual layer was $49 \%$, and (d) with high-viscosity resin, nonuniformity of the residual layer was $5 \%$.

on the viscosity of the photocurable resin. We fabricated 165 dies in a $130 \times 130 \mathrm{~mm}^{2}$ area of an 8 in silicon substrate using only a quartz mold and step-and-repeat UV nanoimprinting under atmospheric pressure. The quartz mold was $10 \times 10 \mathrm{~mm}^{2}$. Nanostructures with sizes from $80 \mathrm{~nm}$ to $3 \mu \mathrm{m}$ width and spacing pattern and $200 \mathrm{~nm}$ in depth were fabricated on the silicon substrate. The nanoimprinting conditions are described in Table 1. Figures 7(a) and 7(b) show a photograph of 165 dies fabricated in one area. Figure 7 (c) shows a part of the photograph of the 165 dies fabricated using high-viscosity resin with a viscosity of $12,000 \mathrm{mPa} \cdot \mathrm{s}$, and fringe was not observed. Figure 7(d) shows a part of the photograph of 165 dies fabricated using low-viscosity photocurable resin with a viscosity of $1,200 \mathrm{mPa} \cdot \mathrm{s}$, and fringe was observed. Figure 8 shows a comparison of residual layer thicknesses between high- and low-viscosity resins. In the case of high-viscosity resin, the residual layer thickness was within $30 \mathrm{~nm} \pm 10 \%$. However, in the case of low-viscosity resin, the residual layer thickness was greater than $50 \mathrm{~nm}$. As shown in Figures 7 and 8 , fabrication of 165 dies was successfully demonstrated by UV nanoimprinting under atmospheric pressure using high-viscosity photocurable resin. Bubble defects were not observed, and the residual layer was uniform.

\section{Discussion}

As shown in Figures 4, 7, and 8, bubble defects and residual layer uniformity depended on the viscosity of the photocurable resin in UV nanoimprinting under atmospheric pressure. Therefore, characteristics of photocurable resin were examined. Figure 9 shows a comparison of four nanoimprinting load profiles using a quartz mold and a silicon substrate. The conditions of the nanoimprint were as follows: from 1,200 to $12,000 \mathrm{mPa} \cdot \mathrm{s}$ of viscosity, a spincoated resin thickness of $2 \mu \mathrm{m}$ and a platen feed velocity of $200 \mathrm{~nm} / \mathrm{s}$. In the case of without resin, the response of load profile was the most linear among the four-load profiles. In the case with high-viscosity, $12,000 \mathrm{mPa} \cdot \mathrm{s}$ of viscosity and delay time was the most increase. As shown in Figure 9, delay time increased with higher-viscosity photocurable resin, because the damping force increased with higher viscosity.

Figure 10 shows the relationship between delay time and nonuniformity of the residual layer. As shown in Figure 10, nonuniformity of the residual layer decreased with longer delay time. As shown in Figures 9 and 10, the uniformity of residual layer thickness depended on the damping characteristics of the photocurable resin. In stepand-repeat UV nanoimprinting under atmospheric pressure, 


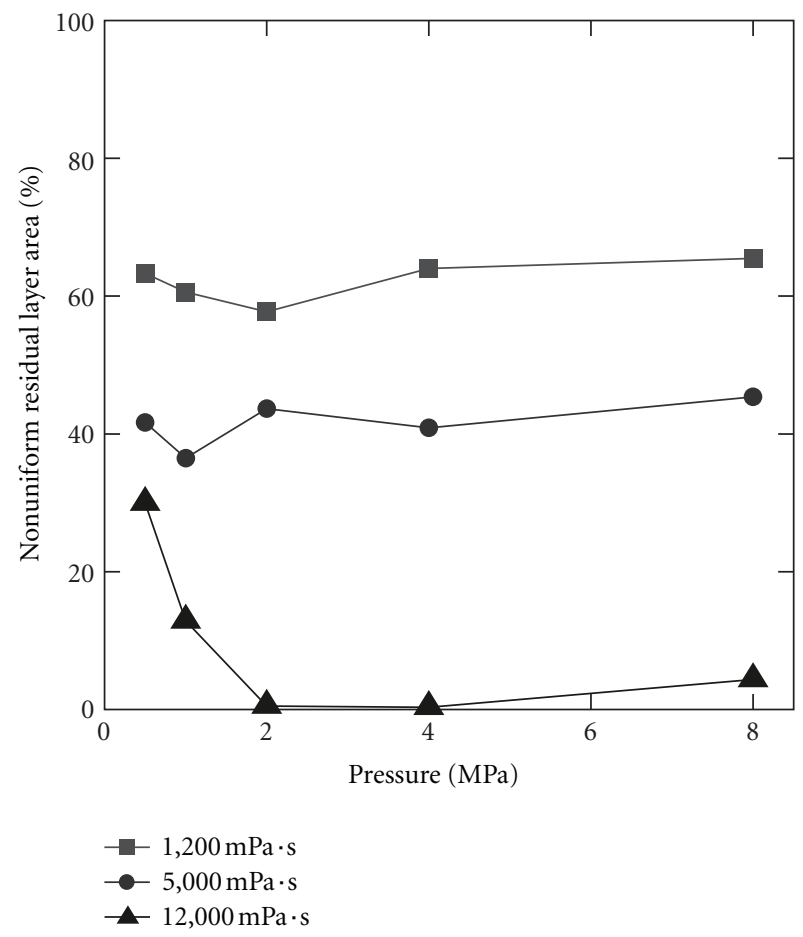

FIGURE 6: Relationship between nonuniformity of the residual layer and imprinting pressure: with low-viscosity resin, the fringe area did not depend on imprinting pressure; with high-viscosity resin, the fringe area was within $10 \%$ using an imprinting pressure $\geq 2 \mathrm{MPa}$.

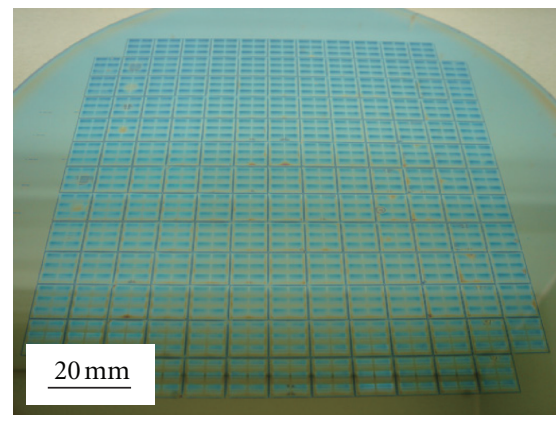

(a)

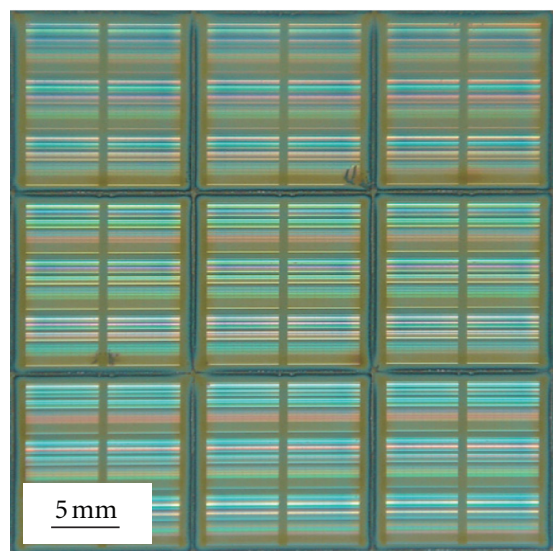

(c)

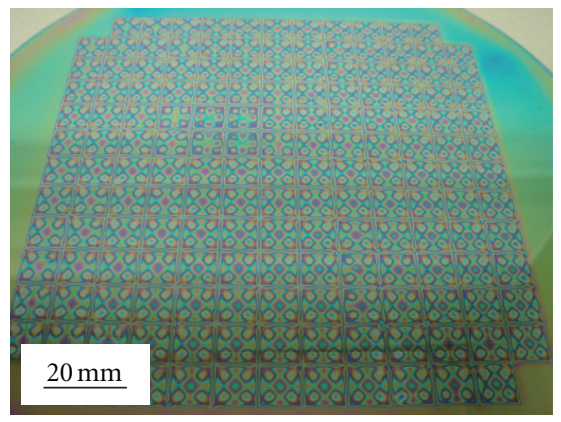

(b)

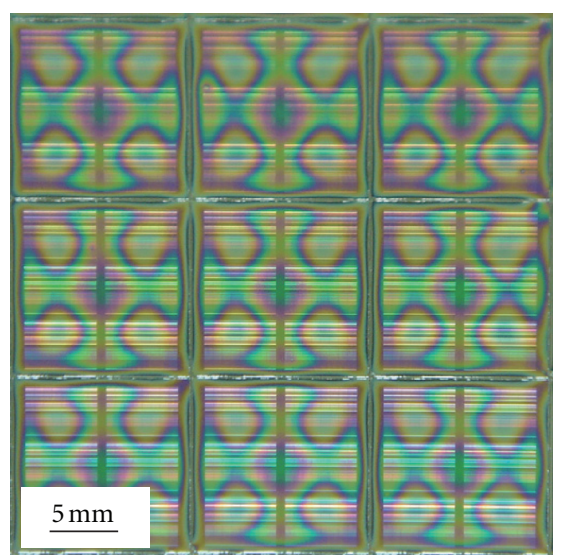

(d)

FIGURE 7: Fabrication of 165 dies on a silicon substrate by step-and-repeat UV nanoimprinting under atmospheric pressure: (a) fabrication of 165 dies using high-viscosity resin (entire area), (b) fabrication of 165 dies using low-viscosity resin (entire area), (c) fabrication of 165 dies using high-viscosity resin, and (d) fabrication of 165 dies using low viscosity resin. 


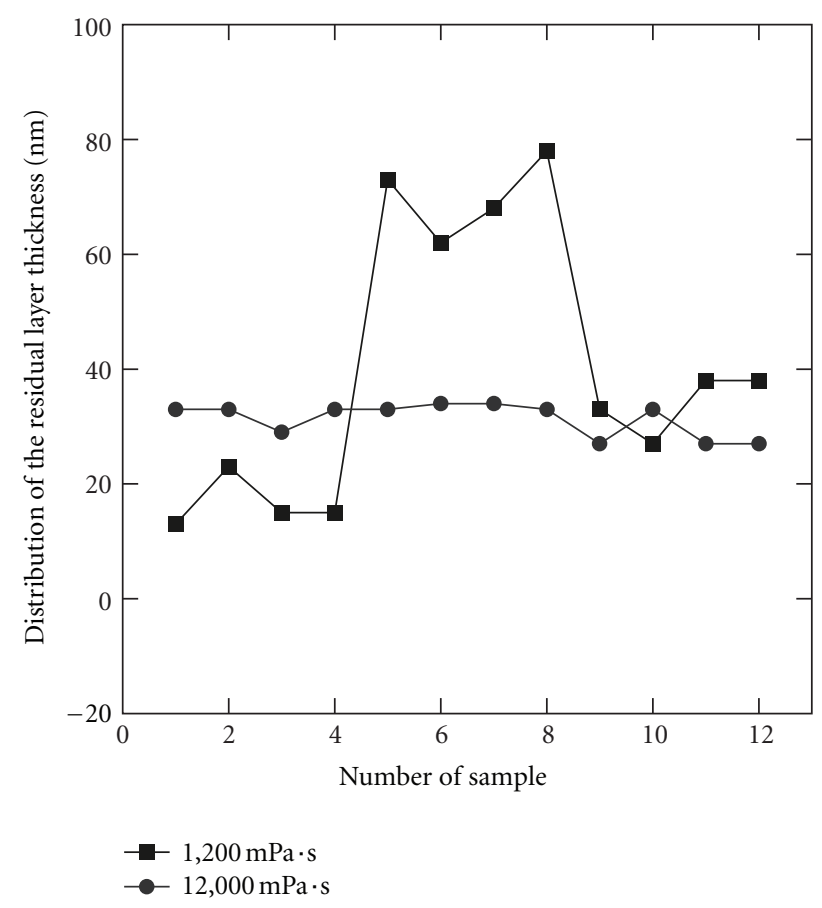

FIGURE 8: Comparison of residual layer thicknesses between high- and low-viscosity resins. With high-viscosity resin, residual layer thickness uniformity was within $30 \mathrm{~nm} \pm 10 \%$; with low-viscosity resin, residual layer thickness uniformity was greater than $50 \mathrm{~nm}$.

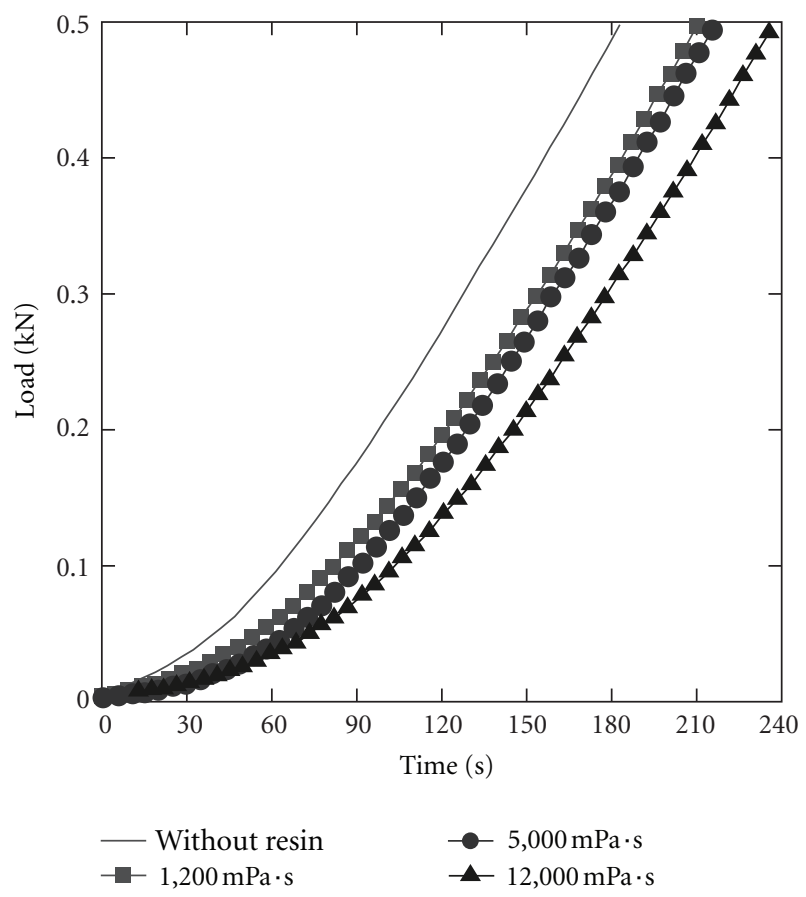

FIGURE 9: Comparison of nanoimprinting load profiles: the solid line is the reference, the square line is the load profile using low-viscosity resin, the circle line is the load profile using middle-viscosity resin, and the triangle line is the load profile using high-viscosity resin. 


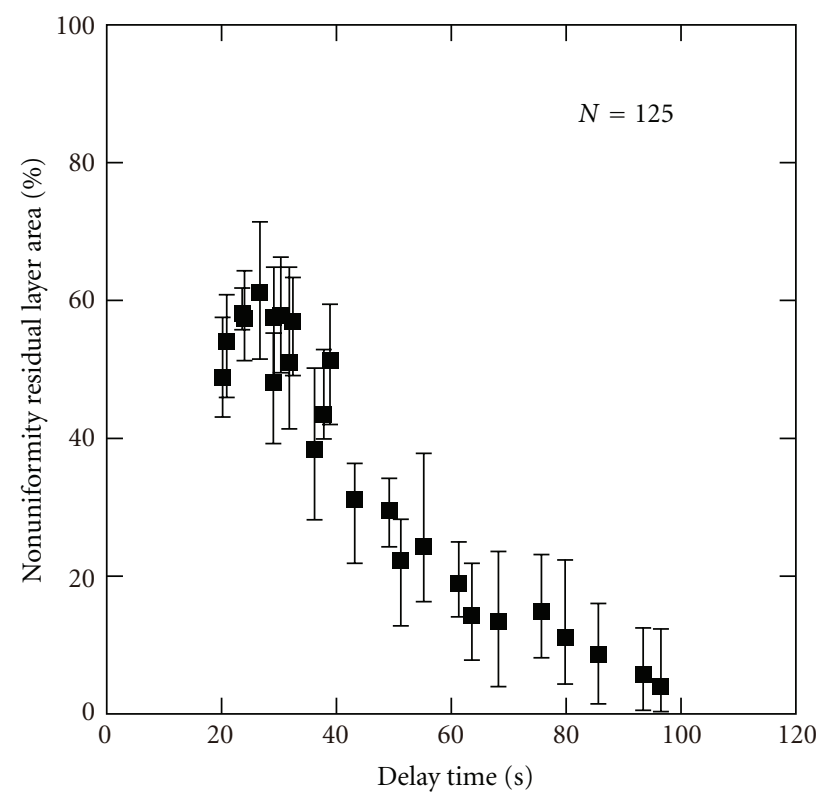

FIGURE 10: Relationship between delay time and nonuniformity of the residual layer: nonuniformity of the residual layer depended on delay time.

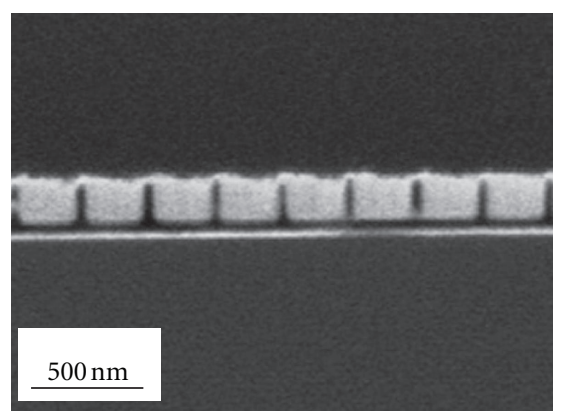

(a)

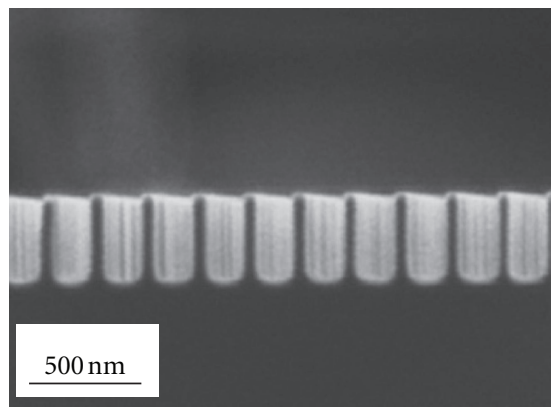

(c)

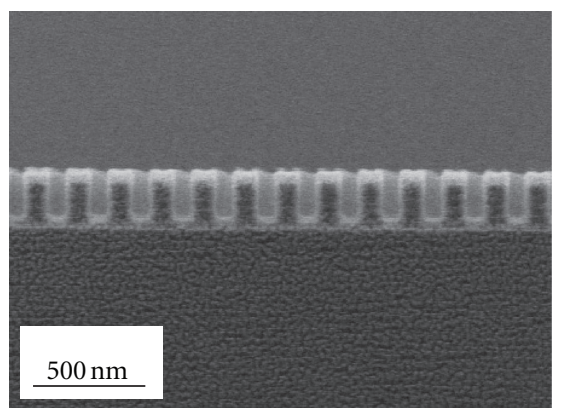

(b)

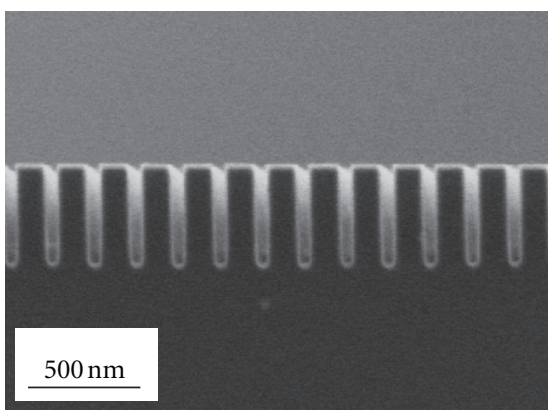

(d)

FIGURE 11: Cross-sectional SEM image: (a) $80 \mathrm{~nm}$ lines and $160 \mathrm{~nm}$ spaces was formed on a silicon substrate by UV nanoimprinting under atmospheric pressure, (b) $100 \mathrm{~nm}$ lines and 100 spaces was formed on a silicon substrate by UV nanoimprinting under atmospheric pressure, (c) $80 \mathrm{~nm}$ lines and $160 \mathrm{~nm}$ spaces was fabricated by a deep RIE system after UV nanoimprinting, (d) $100 \mathrm{~nm}$ lines and $100 \mathrm{~nm}$ spaces was fabricated by a deep RIE system after UV nanoimprinting.

bubble defects and nonuniformity of the residual layer improved by using high-viscosity resin.

Figure 11 shows nanostructures fabricated on a silicon substrate. The conditions for fabrication are shown in Table 2. Figure 11(a) shows an SEM image of nanostructures formed by UV nanoimprinting under atmospheric pressure. Nanostructures with $80 \mathrm{~nm}$ lines and $160 \mathrm{~nm}$ spaces and $200 \mathrm{~nm}$ depths were observed. Residual layer uniformity was $30 \mathrm{~nm}$. Figure 11(b) shows a cross-sectional SEM image of nanostructures. Nanostructures with $100 \mathrm{~nm}$ lines and 100 
TABLE 1: Imprinting conditions for fabrication of 165 dies.

\begin{tabular}{lc}
\hline Spin-coated resin thickness & $200 \mathrm{~nm}$ \\
Photocurable resin viscosity (low) & $1,200 \mathrm{mPa} \cdot \mathrm{s}$ \\
Photocurable resin viscosity (high) & $12,000 \mathrm{mPa} \cdot \mathrm{s}$ \\
Imprinting pressure & $2 \mathrm{MPa}$ \\
Platen feed velocity & $1 \mu \mathrm{m} / \mathrm{s}$ \\
Total UV light exposure & $30 \mathrm{~mW} / \mathrm{cm}^{2}$ \\
1-cycle UV light exposure time & $12 \mathrm{~s}$ \\
Total fabrication time & $3.4 \mathrm{~h}$ \\
1-cycle fabrication time & $74.2 \mathrm{~s}$ \\
Imprinting temperature & Room temperature \\
\hline
\end{tabular}

TABLE 2: Imprinting conditions.

\begin{tabular}{lc}
\hline Spin-coated resin thickness after baking & $120 \mathrm{~nm}$ \\
Photo-curable resin viscosity & $12,000 \mathrm{mPa} \cdot \mathrm{s}$ \\
Imprinting pressure & $2 \mathrm{MPa}$ \\
Imprinting platen feed velocity & $1 \mu \mathrm{m} / \mathrm{s}$ \\
Imprinting total UV light exposure & $360 \mathrm{~mJ} / \mathrm{cm}^{2}$ \\
1-cycle UV light exposure time & $12 \mathrm{~s}$ \\
RIE process gasses & $\mathrm{C}_{4} \mathrm{~F}_{8}, \mathrm{SF}_{6}$ \\
RIE RF power & $500 \mathrm{~W}$ \\
RIE process time & $180 \mathrm{~s}$ \\
\hline
\end{tabular}

spaces and $200 \mathrm{~nm}$ depth were observed. Residual layer uniformity was $30 \mathrm{~nm}$. Figure 11(c) shows a cross-sectional SEM image of nanostructures fabricated by a reactive ion etching (RIE) system (MUC-21, Sumitomo precision products Co., Ltd.). Nanostructures with $80 \mathrm{~nm}$ lines and $160 \mathrm{~nm}$ spaces and $500 \mathrm{~nm}$ depths were observed. Figure 11(d) shows a cross-sectional SEM image of nanostructures. Nanostructures with $100 \mathrm{~nm}$ lines and $100 \mathrm{~nm}$ spaces and $500 \mathrm{~nm}$ depths were observed. As shown in Figure 11, uniformity of the residual layer was a key issue for nanostructure fabrication using reactive ion etching.

\section{Conclusion}

Practical wide-area nanostructure fabrication was demonstrated by reproducing UV nanoimprinting conditions under atmospheric pressure. By examining and optimizing the viscosity of photocurable resin, bubble defects were not observed, and the residual layer uniformity which depended on the damping characteristics of the photocurable resin was improved by optimizing the viscosity of the photocurable resin. This fabrication process and system are applicable as a widely available method for next-generation mass production of large size nanostructures.

\section{Acknowledgments}

This work is partly supported by Japan Ministry of Education, Culture, Sports Science and Technology Grant-in-Aid for Scientific Basic Research (S) no. 23226010 and the Grantin-Aid for Specially Promoted Research, "Establishment of Electrochemical Device Engineering" from the Ministry of Education, Culture, Sports, Science and Technology (MEXT), Japan. The authors thank Nanotechnology Support Project of Waseda University for their technical advices.

\section{References}

[1] S. Y. Chou, P. R. Krauss, and P. J. Renstrom, "Imprint of sub$25 \mathrm{~nm}$ vias and trenches in polymers," Applied Physics Letters, vol. 67, pp. 3114-3116, 1995.

[2] S. Y. Chou, P. R. Krauss, and P. J. Renstrom, "Nanoimprint lithography," Journal of Vacuum Science and Technology B, vol. 14, no. 6, pp. 4129-4133, 1996.

[3] K. J. Byeon, E. J. Hong, H. Park et al., "Full wafer scale nanoimprint lithography for GaN-based light-emitting diodes," Thin Solid Films, vol. 519, no. 7, pp. 2241-2246, 2011.

[4] A. O. Altun, S. Jeon, J. Shim et al., "Corrugated organic light emitting diodes for enhanced light extraction," Organic Electronics, vol. 11, no. 5, pp. 711-716, 2010.

[5] A. Takakuwa, M. Misaki, Y. Yoshida, and K. Yase, "Micropatterning of emitting layers by microcontact printing and application to organic light-emitting diodes," Thin Solid Films, vol. 518, no. 2, pp. 555-558, 2009.

[6] S. Ishizuka, M. Nakao, S. Mashiko, J. Mizuno, and S. Shoji, "Fabrication of uniform gratings on composite semiconductors using UV nanoimprint lithography," Journal of Photopolymer Science and Technology, vol. 22, no. 2, pp. 213217, 2009.

[7] B. L. Cardozo and S. W. Pang, "Patterning of polyfluorene based polymer light emitting diodes by reversal imprint lithography," Journal of Vacuum Science and Technology B, vol. 26, no. 6, pp. 2385-2389, 2008.

[8] K. S. Han, J. H. Shin, W. Y. Yoon, and H. Lee, "Enhanced performance of solar cells with anti-reflection layer fabricated by nano-imprint lithography," Solar Energy Materials and Solar Cells, vol. 95, no. 1, pp. 288-291, 2011.

[9] C. Battaglia, J. Escarré, K. Söderström et al., "Nanoimprint lithography for high-efficiency thin-film silicon solar cells," Nano Letters, vol. 11, no. 2, pp. 661-665, 2011.

[10] J. H. Shin, K. S. Han, and H. Lee, "Anti-reflection and hydrophobic characteristics of M-PDMS based moth-eye nano-patterns on protection glass of photovoltaic systems," Progress in Photovoltaics, vol. 19, no. 3, pp. 339-344, 2011.

[11] C. H. Lin, H. H. Lin, W. Y. Chen, and T. C. Cheng, "Direct imprinting on a polycarbonate substrate with a compressed air press for polarizer applications," Microelectronic Engineering, vol. 88, no. 8, pp. 2026-2029, 2011.

[12] K. Takano, H. Yokoyama, A. Ichii, I. Morimoto, and M. Hangyo, "Wire-grid polarizer sheet in the terahertz region fabricated by nanoimprint technology," Optics Letters, vol. 36, no. 14, pp. 2665-2667, 2011.

[13] S. H. Hong, K. S. Han, K. J. Byeon, H. Lee, and K. W. Choi, "Fabrication of sub-100 nm sized patterns on curved acryl substrate using a flexible stamp," Japanese Journal of Applied Physics, vol. 47, no. 5, pp. 3699-3701, 2008.

[14] C. Auner, U. Palfinger, H. Gold et al., "Residue-free room temperature UV-nanoimprinting of submicron organic thin film transistors," Organic Electronics, vol. 10, no. 8, pp. 14661472, 2009.

[15] D. J. Resnick, W. J. Dauksher, D. Mancini et al., "Imprint lithography for integrated circuit fabrication," Journal of 
Vacuum Science and Technology B, vol. 21, no. 6, pp. 26242631, 2003.

[16] H. Lee, "Effect of imprinting pressure on residual layer thickness in ultraviolet nanoimprint lithography," Journal of Vacuum Science and Technology B, vol. 23, no. 3, pp. 11021106, 2005.

[17] M. Vogler, S. Wiedenberg, M. Mühlberger et al., "Development of a novel, low-viscosity UV-curable polymer system for UV-nanoimprint lithography," Microelectronic Engineering, vol. 84, no. 5-8, pp. 984-988, 2007.

[18] C. C. Wu, S. L. C. Hsu, and W. C. Liao, "A photopolymerization resist for UV nanoimprint lithography," Microelectronic Engineering, vol. 86, no. 3, pp. 325-329, 2009.

[19] X. Ye, Y. Ding, Y. Duan, H. Liu, and B. Lu, "Roomtemperature capillary-imprint lithography for making micro/nanostructures in large areas," Journal of Vacuum Science and Technology B, vol. 28, no. 1, pp. 138-142, 2010.

[20] H. Hiroshima and M. Komuro, "Control of bubble defects in UV nanoimprint," Japanese Journal of Applied Physics Part 1, vol. 46, no. 9, pp. 6391-6394, 2007.

[21] H. Hiroshima and M. Komuro, "UV-nanoimprint with the assistance of gas condensation at atmospheric environmental pressure," Journal of Vacuum Science and Technology B, vol. 25, no. 6, pp. 2333-2336, 2007.

[22] H. Hiroshima, H. Atobe, Q. Wang, and S. W. Youn, "UV nanoimprint in pentafluoropropane at a minimal imprint pressure," Japanese Journal of Applied Physics, vol. 49, no. 6, Article ID 06GL01, 5 pages, 2010.

[23] H. Goto, A. Hagiwara, K. Ishibashi, M. Kokubo, H. Okuyama, and S. Fukuyama, "Micro patterning using UV-nanoimprint process," Journal of Photopolymer Science and Technology, vol. 20, no. 4, pp. 559-562, 2007.

[24] Q. Wang, H. Hiroshima, H. Atobe, and S. W. Youn, "Residual layer uniformity using complementary patterns to compensate for pattern density variation in UV nanoimprint lithography," Journal of Vacuum Science and Technology B, vol. 28, no. 6, Article ID C6M125, 5 pages, 2010.

[25] K. Ishibashi, M. Kokubo, H. Goto, J. Mizuno, and S. Shoji, "Fabrication process for large size mold and alignment method for nanoimprint system," IEEJ Transactions on Sensors and Micromachines, vol. 130, no. 8, pp. 363-368, 2010. 

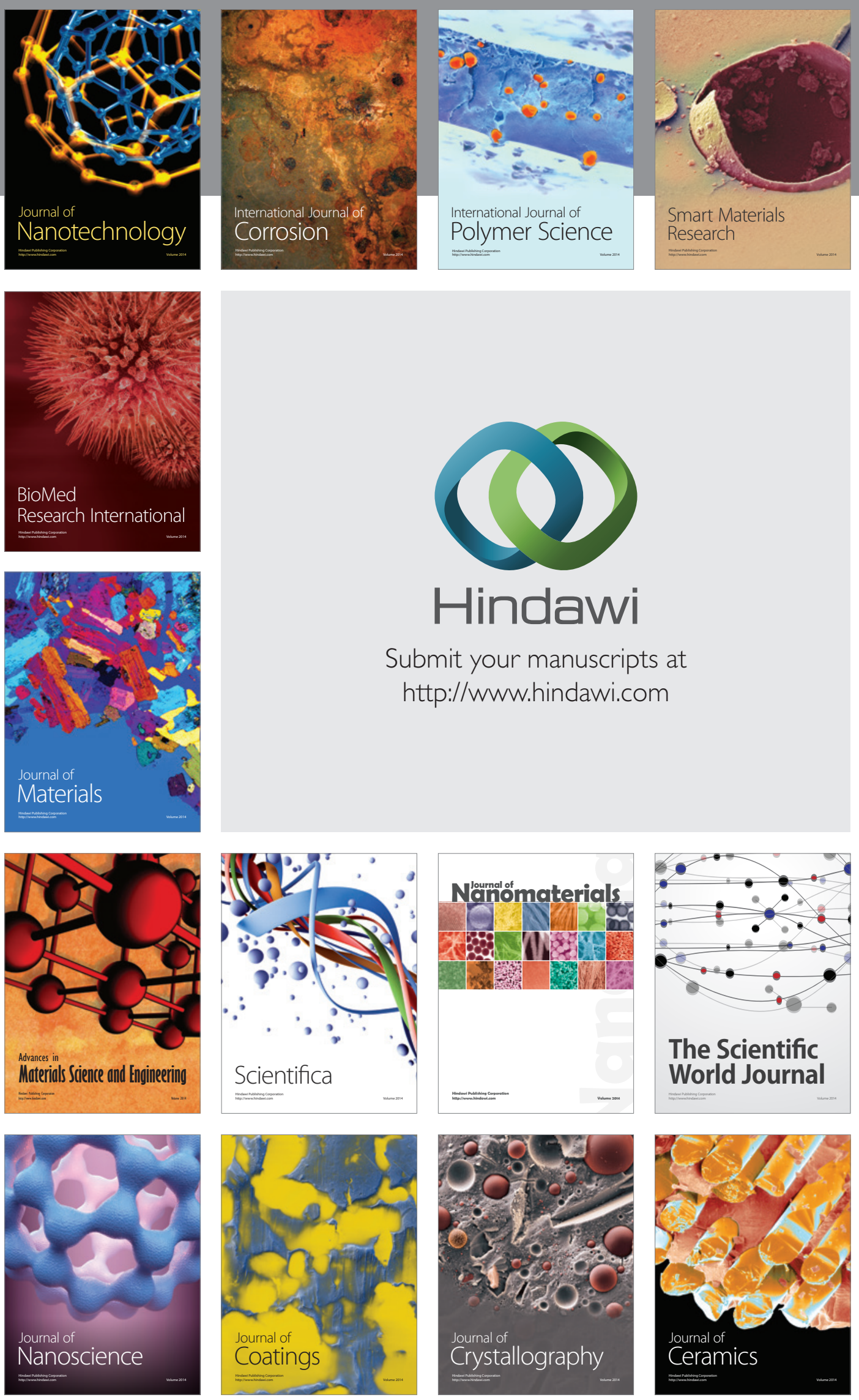

The Scientific World Journal

Submit your manuscripts at

http://www.hindawi.com

\section{World Journal}

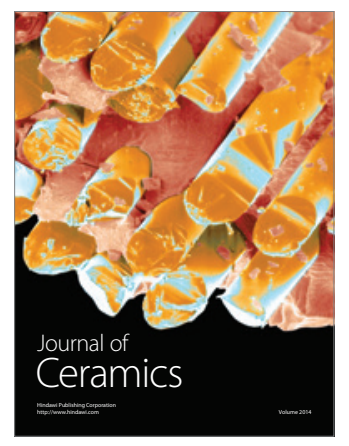

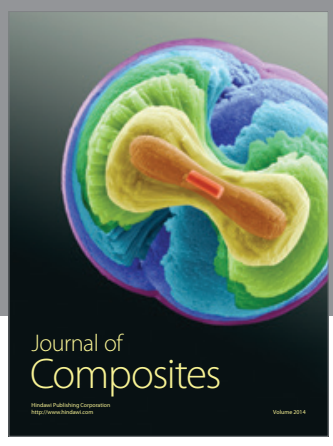
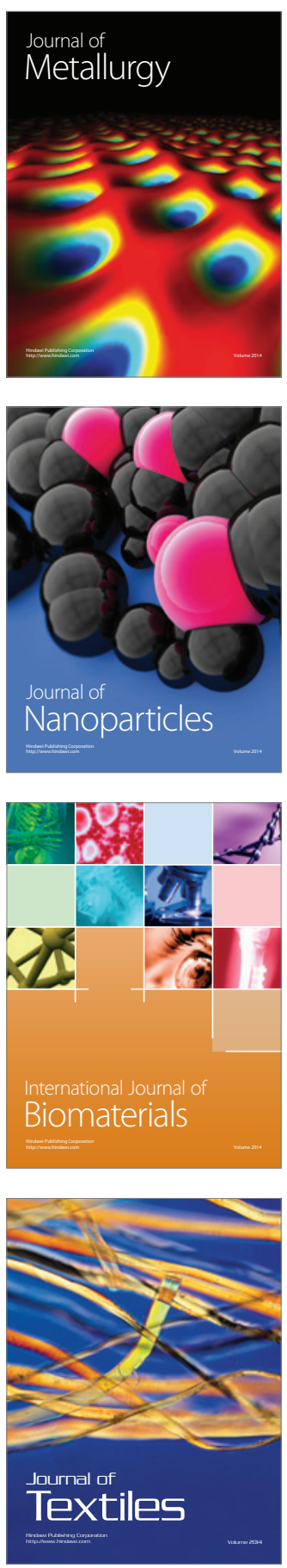